$\begin{array}{llll}\Omega & 0 & \text { Q } \\ \text { P.E. Ronksley' } & \text { 'Department of Community } & \text { Department of Community } & \text { peronksl@ucalgary.ca } \\ \text { B.R. Hemmelgarn }{ }^{1,2} & \text { Health Sciences } & \text { Health Sciences, University } & \\ \text { W.H. Tsai, } & \text { Univartment of Medicine, } & \text { of Calgary, 3280 Hospital } \\ & \text { Calgary, Canada } & \text { Drive NW, Calgary, Alberta, } \\ & \text { T2N 4Z6, Canada }\end{array}$

\title{
Comorbidity and healthcare costs in patients with obstructive sleep apnoea
}

\section{Educational aims}

$\odot$ To provide physicians with knowledge of common comorbid conditions associated with obstructive sleep apnoea (OSA).

○ To emphasise the healthcare burden and costs associated with OSA.

$\odot$ Recognise the role of risk stratification in identifying patients who are likely to develop OSA-related complications.

\section{Summary}

OSA is common, with an estimated prevalence of up to $20 \%$. Observational studies have found OSA to be associated with increased cardiovascular morbidity, mortality and healthcare costs. Continuous positive airway pressure (CPAP) has been shown to be an effective therapy for OSA. Unfortunately, clinical trials assessing the effectiveness of CPAP to mitigate associated morbidity are limited and those that have been conducted show variable findings, with not all patients benefiting from treatment. Given the prevalence of OSA in the general population, treatment of all individuals would be costly and unnecessary. Recent work suggests that the heterogeneity in clinical trial results may be driven by the inability to identify at-risk groups. Identifying patients with clinically relevant sequelae may be useful for targeting treatment to those at greatest risk. In this review, we discuss the potential association between OSA and comorbid conditions, as well as the economic and health impact of such associations. We also highlight the importance of risk stratification in identifying patients who are likely to develop OSArelated complications and adverse health outcomes.

Obstructive sleep apnoea (OSA) is a disorder characterised by episodic cessation of breathing during sleep with intermittent hypoxaemia and sleep fragmentation. Population-based studies estimate the prevalence of clinically significant OSA to be approximately $3-7 \%$ for
Statement of interest None declared.
HERMES syllabus link: module B.19.1 
adult males and $2-5 \%$ for adult females in the general population $[1-3]$. Despite the prevalence of this condition, OSA often goes undiagnosed. Research has demonstrated that the majority of primary care physicians are limited in their ability to recognise the presence of OSA syndrome. While many physicians understand the algorithms for the diagnosis of sleep apnoea, the majority could not identify the patients for whom diagnostics were needed [4].

Obesity is a well-established risk factor for OSA [5]. It is estimated that more than half of the prevalence of OSA is attributable to excess body weight. After adjustment for obesity, the prevalence of OSA may be closer to $20 \%$ [6]. Associated health expenditures in obese individuals are $42 \%$ greater than people with a normal body weight and approximately $9 \%$ of annual health expenditures in North America are related to obesity [7]. This is in large part related to the increase in obesity-related medical conditions, such as diabetes mellitus and cardiovascular disease. In parallel, OSA has also been associated with hypertension, coronary artery disease, stroke and diabetes [8-11]. However, separating independent OSA-related contribution to morbidity from that of obesity can be difficult.

\section{OSA and associated morbidity}

\section{Hypertension}

Untreated, OSA may lead to a number of adverse cardiovascular consequences. Specifically, large cross-sectional studies have shown an association between OSA and hypertension $[9,12]$. The Sleep Heart Health Study was one of the first multicentre cohort studies to demonstrate that OSA was an independent risk factor for systemic hypertension [9]. They showed that adults with moderate-to-severe OSA were at increased risk for hypertension after controlling for body mass index (BMI), neck circumference, alcohol intake, smoking and sex (OR 1.37, 95\% Cl 1.03-1.83). A prospective analysis of the Wisconsin Sleep Cohort also showed that even a slightly elevated apnoea-hypopnea index (AHI) $(<5$ events per h) was associated with a $42 \%(95 \% \mathrm{Cl} 13-78 \%)$ increase in the odds of incident hypertension over a 4-year follow-up period [12]. Furthermore, a dose-response relationship was observed for more severe categories of OSA, with an odds ratio of 2.89
(95\% Cl 1.46-5.64) for an $\mathrm{AHI}$ of $\geqslant 15$ versus 0 events per $h$.

\section{Coronary artery disease/stroke}

OSA is also associated with cardiovascular/ cerebrovascular outcomes, including myocardial infarction (MI) and stroke [8, 13-15]. Case-control studies of patients assessed for OSA after MI support an association between the two conditions, with odd ratios ranging from 4.1 to 4.5 in males and females $[14,15]$. A cross-sectional study of a large Spanish cohort referred to a sleep clinic showed that untreated patients with severe OSA had a significantly increased risk of fatal (OR 2.87, 95\% Cl 1.17-7.51) and nonfatal (OR $3.17,95 \% \mathrm{Cl} 1.12-7.51)$ cardiovascular events compared with healthy participants [8].

Similarly, OSA is common in patients that have had a stroke, and often results in worse functional outcomes and higher mortality [16, 17]. Research suggests that moderate-to-severe OSA is an independent risk factor for stroke, although the best available evidence argues that this risk may be limited to those with severe OSA [8]. There is also growing evidence to suggest that stroke patients with OSA are at an increased risk of death [18, 19], while others found these associations may best be characterised as a composite end-point of stroke and mortality, given the low rates of stroke and years of follow-up required to ensure sufficient power to detect significant differences between groups [11].

\section{Diabetes}

OSA and type 2 diabetes are common disorders that often coexist. It is estimated that approximately $50 \%$ of patients with diabetes have OSA [20]. These two conditions also share modifiable risk factors, including obesity. Observational studies have shown that OSA is independently associated with glucose intolerance and insulin resistance $[21,22]$. Recent studies have extended this work and found OSA to be associated with diabetes $[10,23,24]$, although studies assessing the risk of incident diabetes have either shown no association [10] or a very weak association in subjects with moderate-to-severe OSA [23]; thus, whether it is truly causal remains to be determined.

The review provided above highlights the more commonly described medical conditions that have been associated with OSA. Other conditions that have been described to 
be associated with OSA [25-28] are summarised in table 1.

\section{Economic burden of OSA}

Given the association between OSA and cardiovascular or metabolic pathology, it is not surprising that OSA patients use a significant amount of healthcare resources. Case-control studies have consistently shown that OSA patients use more physician services and are admitted to hospital at greater rates in the years prior to diagnosis when compared with subjects without OSA [29-36]. Early work by KRYGER et al. [32] estimated that healthcare utilisation among patients with OSA was twice that of age- and sex-matched controls. Healthcare use was particularly high in those with severe OSA. A casecontrol study of 97 obese patients with severe OSA reported that in the 2 years prior to diagnosis, OSA patients spent 251 nights in the hospital compared with 90 nights for the control group $(p<0.001)$. A more recent case-control study by REUVENI et al. [33] reported similar findings amongst a cohort of young (22-39 years) and middle-aged (40-64 years) adult males with OSA. Patients with OSA used almost twice the healthcare resources (hospitalisations, emergency department visits and physician consultations) as age- and sex-matched controls in the 5-year period prior to OSA diagnosis. Table 2 provides a summary of selected studies assessing healthcare utilisation among OSA patients.

Table 1. Summary of epidemiological evidence for potential associations between obstructive sleep apnoea (OSA) and cardiovascular and metabolic diseases

\begin{tabular}{|c|c|c|c|}
\hline $\begin{array}{l}\text { Medical } \\
\text { condition }\end{array}$ & Study design & $\begin{array}{l}\text { Data } \\
\text { support } \\
\text { significant } \\
\text { association }\end{array}$ & Comments \\
\hline \multirow[t]{2}{*}{ Hypertension } & Cross sectional (prevalence) & Yes & \multirow{2}{*}{$\begin{array}{l}\text { Cross sectional studies have shown that OSA is associated } \\
\text { with hypertension independent of obesity } \\
\text { Adults with OSA are almost } 3 \text { times more likely to develop } \\
\text { hypertension compared to those with no OSA }\end{array}$} \\
\hline & Prospective cohort (incidence) & Yes & \\
\hline \multirow{2}{*}{$\begin{array}{l}\text { Coronary heart } \\
\text { disease }\end{array}$} & Cross sectional (prevalence) & Yes & \multirow{2}{*}{$\begin{array}{l}\text { Adults with severe OSA (AHI }>30 \text { events per } h \text { ) have more } \\
\text { fatal and nonfatal cardiovascular events } \\
\text { No prospective data assessing OSA and risk of developing } \\
\text { coronary heart disease in adult populations }\end{array}$} \\
\hline & Prospective cohort (incidence) & NA & \\
\hline \multirow[t]{2}{*}{ Stroke } & Cross sectional (prevalence) & Yes & \multirow{2}{*}{$\begin{array}{l}\text { OSA is common in patients that have had a stroke } \\
\text { Moderate-to-severe OSA is an independent risk factor for } \\
\text { stroke } \\
\text { Severe OSA is a risk for development of ischaemic stroke }\end{array}$} \\
\hline & Prospective cohort (incidence) & Yes & \\
\hline \multirow{2}{*}{$\begin{array}{l}\text { Metabolic } \\
\text { disorders }\end{array}$} & Cross sectional (prevalence) & Yes & \multirow{2}{*}{$\begin{array}{l}\text { OSA is associated with insulin resistance, glucose } \\
\text { intolerance and type } 2 \text { diabetes } \\
\text { Prospective studies assessing the risk of developing } \\
\text { diabetes show conflicting results or show weak } \\
\text { associations at best }\end{array}$} \\
\hline & Prospective cohort (incidence) & Yes & \\
\hline \multirow[t]{2}{*}{ Heart failure } & Cross sectional (prevalence) & Yes & \multirow{2}{*}{$\begin{array}{l}\text { Adults with OSA are } 2 \text { times more likely to have heart } \\
\text { failure after adjusting for important confounders } \\
\text { No prospective data assessing OSA and risk of developing } \\
\text { left ventricular hypertrophy or heart failure }\end{array}$} \\
\hline & Prospective cohort (incidence) & NA & \\
\hline \multirow[t]{2}{*}{ Atrial fibrillation } & Cross sectional (prevalence) & Yes & \multirow{2}{*}{$\begin{array}{l}\text { Atrial fibrillation common in OSA patients } \\
\text { OSA is independently associated with atrial fibrillation, } \\
\text { though no data are available to support the risk of incident } \\
\text { events }\end{array}$} \\
\hline & Prospective cohort (incidence) & NA & \\
\hline
\end{tabular}

NA: not available; AHI: apnoea-hypopnoea index. 


\section{Educational questions}

1) Which of the following statements about CPAP is correct? a) CPAP is not considered a cost-effective treatment for OSA.

b) CPAP is effective at reducing daytime hypersomnolence and improving quality of life.

c) All patients will benefit from CPAP regardless of OSA severity.

d) The use of CPAP has been convincingly shown to reduce healthcare costs and decrease the risk of adverse outcomes in OSA patients.

2) The effect of treatment on risk reduction in OSA patients is less than clear. Recent work suggests that the observed heterogeneity in clinical trials may be driven by the inability to identify at-risk groups. Which of the following characteristics may improve targeting of at risk patients?

a) Excessive daytime sleepiness

b) Oxygen desaturation profile

c) Increased healthcare utilisation

d) All of the above

3) Epidemiological studies have found the following health conditions to be associated with OSA except:
The subsequent cost associated with healthcare use in OSA patients is significant. RONALD et al. [34] examined healthcare use and costs in a group of 181 OSA patients, and reported that OSA patients used twice the resources compared with age-, sex- and geographically matched controls in the 10-year period prior to diagnosis. Specifically, the physician claims for OSA patients totalled CA $\$ 686,365$ ( $\$ 3,972$ per patient) compared with $\$ 356,376$ (\$1,969 per patient) over the 10-year study period [34]. Similarly, KAPUR et al. [39] calculated a mean annual cost prior to diagnosis of $\$ 2,720$ using administrative data available within a health maintenance organisation in Washington State (USA). They also found a dose-response relationship between OSA severity and healthcare use within this same data source. Based on a prevalence of moderate-to-severe undiagnosed OSA in the general population $(2 \%)$, they estimated the annual cost of treating the medical consequences of OSA to be $\$ 3.4$ billion in the USA [39]. This economic burden is likely to be far greater when indirect costs associated with OSA (absence from work and lost productivity, costs of illnessrelated accidents, etc.) are also considered in the estimation of cost. For example, OSA-related motor vehicle accidents alone in 2000 were estimated to cost over $\$ 15$ billion [40].

\section{Limitations of prior studies}

Despite the relatively consistent findings of increased healthcare use across different study populations, the magnitude of these findings remains unclear, and there are several limitations in study design. The majority of casecontrol studies were unable to control for differences in BMI between OSA cases and controls, and thus increased healthcare use may have been driven by obesity-related differences between groups. However, BANNo et al. [30] recently found physician fees and visits to be higher in 223 obese females with OSA when compared with obese controls, suggesting that OSA may be an independent predictor of increase healthcare use. Still, it is difficult to conclude that higher healthcare use and costs in the years prior to diagnosis is related to untreated OSA when case selection may be biased by factors associated with healthcare use. A commentary by KAPUR et al. [41] discusses how subjects who seek healthcare more frequently may be more likely to be diagnosed with OSA compared with subjects who have less illness. This may partially explain major differences in healthcare use between cases and controls. Furthermore, matching on a limited number of characteristics, such as age, sex, obesity, residence and family physician, may not adequately adjust for differences between cases and controls, and pose a threat to validity.

Population-based studies examining the association between OSA and healthcare use have attempted to eliminate some of the biases identified above. The Sleep Heart Health Study was the first to show an increase in healthcare use in a sample of 6,440 adults. Multivariate analysis found an $18 \%$ increase in healthcare use in OSA subjects compared with those with no OSA after adjusting for multiple clinical factors [37]. However, this study employed an indirect measure of healthcare utilisation through the use of a modified chronic disease score calculated from medication data. The modified chronic disease score has been shown to correlate with ambulatory visits, hospitalisations and mortality, and represents the expected healthcare use within a defined period; however, it may not reflect the true magnitude of the relationship between OSA and healthcare use. Our group has expanded upon this work by using direct measures of healthcare utilisation, and we also found an increased rate of healthcare utilisation among subjects with severe OSA and excessive daytime sleepiness compared to those with less severe OSA, albeit only to modest effect [38].

\section{The role of CPAP}

Continuous positive airway pressure (CPAP) is the gold standard treatment for OSA, and is effective at reducing daytime hypersomnolence and improving quality of life [42]. However, little is known about the effect of CPAP on reducing healthcare use and associated cost. Few studies have reported an association between CPAP use and healthcare utilisation $[29,43]$. Those that are published have similar flaws, including limited generalisability, small sample size, and inadequate adjustment for comorbidity and obesity. In a small study of 88 OSA patients with severe cardiovascular and pulmonary disease, a significant decrease in hospitalisation for these illnesses was found after the initiation of nasal CPAP among 19 patients who reported regular use [43]. A larger prospective cohort study included 344 OSA patients and compared the difference in healthcare costs between cases 
and controls for a period before and after initiation of CPAP [29]. They found the difference in physician claims and hospitalisations between the OSA patients and a group of randomly selected age-, sex- and socioeconomic statusmatched controls was significantly less in the 2-year period after diagnosis and treatment compared with the difference in the year prior to diagnosis. However, patients were not matched based on comorbidities or BMI. Post hoc analysis also revealed that the differences were only significant in the group of patients who reported being compliant with CPAP therapy.

Although a reduction in healthcare utilisation and medical costs has not been convincingly demonstrated in diverse adult patient populations with OSA after therapy, results from cost-effectiveness analyses strongly support the cost-effectiveness of CPAP in patients with moderate-to-severe OSA. This is in large part related to an unequivocal benefit in patient-reported quality of life. Studies have provided estimates ranging from $\$ 2,000$ to $\$ 11,000$ per quality-adjusted life-year (QALY) over a 5-year period for treating moderate-tosevere OSA [44, 45]. Compared with other standard medical therapies, such as blood pressure lowering medications for hypertension (\$10,000-57,000 per QALY) and oral hypoglycaemics for diabetics $(\sim \$ 34,000$ per QALY), CPAP would be considered to be of good value from a health provider perspective $[39,46]$.

\section{CPAP and health outcomes}

Despite benefit from CPAP using cost effectiveness data, the evidence that CPAP improves health outcomes is mixed. While numerous studies have demonstrated benefit from CPAP at the individual level, not all patients benefit from treatment. Currently, there are no standard criteria that can be applied a priori to identify the subgroup of patients who will benefit from treatment. Traditional measures of OSA severity, such as the polysomnographically determined $\mathrm{AHI}$, do not reliably predict those who will benefit from CPAP therapy [47]. This presents a major challenge for healthcare providers and funding authorities. Given the high prevalence of disease in the general population, diagnosis and treatment of all patients with OSA would be costly and unnecessary. In order to control costs, many jurisdictions have placed arbitrary limits on both access to diagnostic testing and CPAP funding. This often results in no funding, unacceptably long waiting times and inappropriate allocation of resources [48]. This is further complicated by the fact there are limited clinical trial data to support the benefits of CPAP for various health outcomes. Specifically, the results show significant heterogeneity in the ability of CPAP to reduce risk in OSA patients.

\section{CPAP and hypertension}

Previous systematic reviews and meta-analyses of randomised, placebo-controlled trials have assessed the ability of CPAP to improve systemic hypertension [49-51]. Although the results from these reviews have been variable, the majority have shown a statistically significant net reduction in blood pressure with CPAP as compared with a control group. These reviews have also shown blood pressure reduction to be greater in patients with more severe OSA or sleep fragmentation, and those with greater adherence to CPAP therapy. Unfortunately, many of the included studies within these reviews have been limited by small sample size and to patients with severe OSA. This results in significant heterogeneity and large confidence intervals around the pooled estimates. Furthermore, the observed reductions in blood pressure are small, ranging from 1 to $2 \mathrm{mmHg}$, bringing into question the clinical significance of these findings (table 3 ).

Given the limitations in previous trials, international, multicentre randomised controlled trials (RCTs) have been initiated to assess whether CPAP can reduce cardiovascular risk in OSA patients, including the Multicentre Obstructive Sleep Apnoea Interventional Cardiovascular Trial (MOSAIC) and Sleep Apnea Cardiovascular Endpoints Study (SAVE). These represent the largest prospective RCTs conducted to date to assess this association and will help inform us whether there is differential risk across OSA subgroups. Although the results have not been published, preliminary findings from the MOSAIC trial suggest that 6 months of CPAP in minimally symptomatic OSA is associated with a cost-effective reduction in daytime sleepiness, but does not reduce cardiovascular risk [52].

\section{CPAP and diabetes}

The effect of treatment of OSA on glucose metabolism and glycaemic control has also been investigated with conflicting results. WEST et al. [53] a) Hypertension

b) Diabetes

c) Chronic obstructive pulmonary disease

d) Heart failure

4) Which of the following statements about OSA and healthcare utilisation is false?

a) OSA patients consume up to three times more healthcare resources than ageand sex-matched controls.

b) CPAP has been conclusively shown to reduce healthcare costs.

c) CPAP is a costeffective treatment for OSA, particularly when compared with treatments in other chronic conditions.

d) OSA patients with excessive daytime sleepiness and hypoxaemia have been shown to increase healthcare use in observational studies.

5) Clinical trial results show significant heterogeneity in the ability of CPAP to reduce risk in OSA patients. This may be a result of:

a) Limitations in study design, such as inadequate control of confounding variables in nonrandomised trials.

b) Issues of CPAP compliance.

c) Inability to accurately identify at-risk groups.

d) All of the above. 


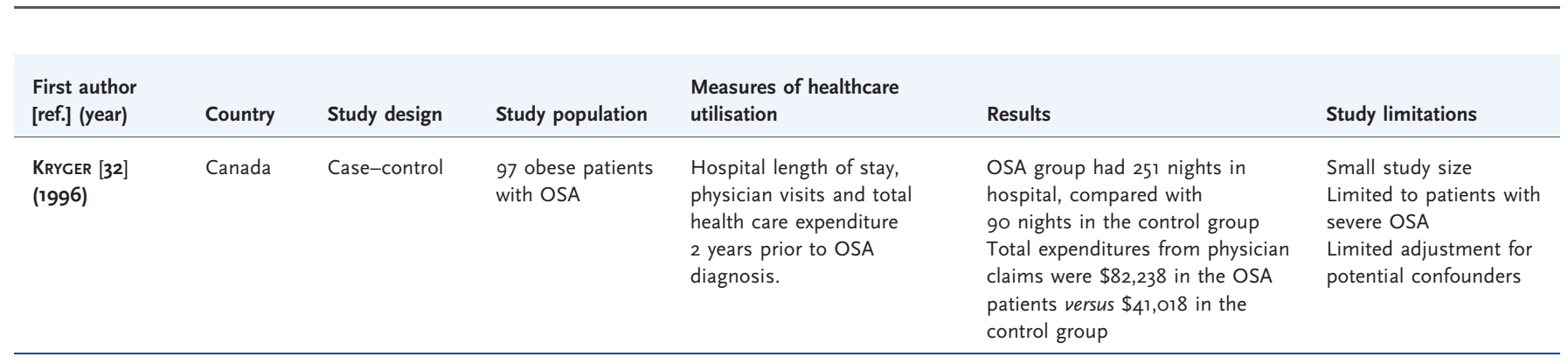

\begin{tabular}{llll}
\hline $\begin{array}{l}\text { Bahammam [29] Canada } \\
\text { (1999) }\end{array}$ & $\begin{array}{l}\text { Prospective } \\
\text { cohort study }\end{array}$ & 344 OSA patients & $\begin{array}{l}\text { Physician claims and } \\
\text { hospitalisations } 2 \text { years } \\
\text { before and after OSA } \\
\text { diagnosis }\end{array}$ \\
&
\end{tabular}

The difference in physician claims between the patients and their matched controls 2 years after diagnosis and treatment was mean \pm SE $\$ 174 \pm 32.4$ per year This was significantly less than the difference in the year before diagnosis $\$ 260 \pm 35.7$

\begin{tabular}{lll}
\hline $\begin{array}{l}\text { Ronald [34] Canada } \\
\text { (1999) }\end{array}$ & Case-control 181 OSA patients & $\begin{array}{l}\text { Physician claims and } \\
\text { hospital length of stay } \\
\end{array}$ \\
& & 10 years prior to OSA \\
& diagnosis
\end{tabular}

OSA patients used twice the resources in the 10 years prior to their diagnosis Physician claims for cases totalled $\$ 686,365$ ( $\$ 3,972$ per patient) compared with $\$ 356,376(\$ 1,969$ per patient) for the controls during the length of the study

\begin{tabular}{|c|c|c|c|c|c|c|}
\hline $\begin{array}{l}\text { SMITH [35] } \\
(2002)\end{array}$ & Canada & Case-control & 773 OSA patients & $\begin{array}{l}\text { Physician fees, physician } \\
\text { visits and hospital nights } \\
5 \text { years prior to OSA } \\
\text { diagnosis }\end{array}$ & $\begin{array}{l}\text { OSA patients used } 23-50 \% \\
\text { more resources in the } 5 \text { years } \\
\text { prior to diagnosis than did } \\
\text { control subjects }\end{array}$ & $\begin{array}{l}\text { Limited to patients with } \\
\text { severe OSA } \\
\text { Limited adjustment for } \\
\text { potential confounders }\end{array}$ \\
\hline $\begin{array}{l}\text { KAPUR [37] } \\
(2002)\end{array}$ & USA & $\begin{array}{l}\text { Cross- } \\
\text { sectional study }\end{array}$ & $\begin{array}{l}6440 \text { Sleep } \\
\text { Heart Health } \\
\text { participants }\end{array}$ & $\begin{array}{l}\text { Determined by a } \\
\text { modified chronic } \\
\text { disease score based } \\
\text { on medication data }\end{array}$ & $\begin{array}{l}\text { Patients with OSA had an } 18 \% \\
\text { increase in healthcare use } \\
\text { compared with patients with } \\
\text { no OSA }\end{array}$ & $\begin{array}{l}\text { Outcome definition was } \\
\text { an indirect measure of } \\
\text { healthcare utilisation }\end{array}$ \\
\hline $\begin{array}{l}\text { TARASIUK [36] } \\
(2005)\end{array}$ & Israel & $\begin{array}{l}\text { Prospective } \\
\text { case-control }\end{array}$ & 218 OSA patients & $\begin{array}{l}\text { Hospitalisation days, } \\
\text { consultations and cost } \\
\text { of drugs } 2 \text { years prior } \\
\text { to OSA diagnosis }\end{array}$ & $\begin{array}{l}\text { Healthcare utilisation was } \\
1.7 \text {-fold higher in the OSAS } \\
\text { patients compared with } \\
\text { controls }\end{array}$ & $\begin{array}{l}\text { Limited adjustment for } \\
\text { potential confounders }\end{array}$ \\
\hline $\begin{array}{l}\text { GREENBERG- } \\
\text { DotAN [31] } \\
(2007)\end{array}$ & Israel & Case-control & $\begin{array}{l}289 \text { males and } \\
289 \text { females } \\
\text { with OSA }\end{array}$ & $\begin{array}{l}\text { Hospitalisations, emergency } \\
\text { department visits, visits to } \\
\text { specialists and prescriptions } \\
\text { supplied } 5 \text { years prior } \\
\text { to diagnosis }\end{array}$ & $\begin{array}{l}\text { Compared with controls, total } \\
5 \text {-year healthcare costs were } 1.8 \\
\text { times higher for both females } \\
\text { and males with OSA } \\
\text { Compared with males with OSA, } \\
\text { expenditures for women with } \\
\text { OSA are } 1.3 \text { times higher }\end{array}$ & $\begin{array}{l}\text { Limited adjustment for } \\
\text { potential confounders }\end{array}$ \\
\hline $\begin{array}{l}\text { REUVENI [33] } \\
(2008)\end{array}$ & Israel & Case-control & $\begin{array}{l}117 \text { young and } 117 \\
\text { middle-aged male } \\
\text { OSA patients }\end{array}$ & $\begin{array}{l}\text { Hospitalisations, emergency } \\
\text { department visits, visits to } \\
\text { specialists and prescriptions } \\
\text { supplied } 5 \text { years prior to } \\
\text { diagnosis }\end{array}$ & $\begin{array}{l}\text { Healthcare utilisation for the } \\
5 \text {-year period was } \geqslant 1.9 \text { times } \\
\text { higher in young and middle- } \\
\text { aged male OSA patients } \\
\text { compared with controls }\end{array}$ & $\begin{array}{l}\text { Sample exclusively male } \\
\text { Limited adjustment for } \\
\text { potential confounders }\end{array}$ \\
\hline $\begin{array}{l}\text { BANNO [30] } \\
(2009)\end{array}$ & Canada & $\begin{array}{l}\text { Retrospective } \\
\text { observational } \\
\text { study }\end{array}$ & $\begin{array}{l}223 \text { obese } \\
\text { females with OSA }\end{array}$ & $\begin{array}{l}\text { Physician fees and visits in } \\
\text { the years prior to OSA } \\
\text { diagnosis }\end{array}$ & $\begin{array}{l}\text { Physician visits } 1 \text { year before } \\
\text { diagnosis in the OSA cases } \\
\text { were more frequent than in the } \\
\text { obese controls: } 13.2 \pm 0.73 \\
\text { versus } 7.26 \pm 0.49 \text { visits }\end{array}$ & $\begin{array}{l}\text { Sample exclusively } \\
\text { female } \\
\text { Limited adjustment for } \\
\text { potential confounders }\end{array}$ \\
\hline $\begin{array}{l}\text { RONKSLEY [38] } \\
(2011)\end{array}$ & Canada & $\begin{array}{l}\text { Cross- } \\
\text { sectional study }\end{array}$ & $\begin{array}{l}2149 \text { patients } \\
\text { referred for sleep } \\
\text { testing }\end{array}$ & $\begin{array}{l}\text { Physician claims, emergency } \\
\text { department visits and } \\
\text { hospitalisations }\end{array}$ & $\begin{array}{l}\text { Patients with severe OSA and } \\
\text { daytime sleepiness had a } 22 \% \\
\text { increase in healthcare use } \\
\text { compared to those with less } \\
\text { severe OSA }\end{array}$ & $\begin{array}{l}\text { Referred population } \\
\text { resulting in limited } \\
\text { generalisability of } \\
\text { results }\end{array}$ \\
\hline
\end{tabular}

Sample exclusively male Limited adjustment for potential confounders

Small study size Limited adjustment for potential confounders 
Table 3. Summary of systematic reviews and meta-analyses: randomised trials of effect of continuous positive airway pressure (CPAP) on hypertension in obstructive sleep apnoea (OSA) patients

\begin{tabular}{|c|c|c|c|c|c|}
\hline $\begin{array}{l}\text { First author } \\
\text { [ref.] }\end{array}$ & Year & $\begin{array}{l}\text { Number of } \\
\text { pooled studies }\end{array}$ & $\begin{array}{l}\text { Outcomes of } \\
\text { interest }\end{array}$ & Results & $\begin{array}{l}\text { Conclusions drawn by } \\
\text { authors }\end{array}$ \\
\hline BAZZANO [50] & 2007 & $\begin{array}{l}16 \text { RCTs } \\
\text { (7 crossover } \\
\text { design, } 9 \\
\text { parallel design) }\end{array}$ & $\begin{array}{l}\text { Mean change } \\
\text { in systolic and } \\
\text { diastolic BP } \\
\text { Mean change } \\
\text { in MAP }\end{array}$ & $\begin{array}{l}\text { Systolic BP }-2.46 \\
(-4.30--0.62) \mathrm{mmHg} \\
\text { Diastolic BP }-1.83 \\
(-3.05--0.61) \mathrm{mmHg} \\
\text { MAP }-2.22 \\
(-4.38--0.05) \mathrm{mmHg}\end{array}$ & $\begin{array}{l}\text { CPAP decreases BP } \\
\text { among those with OSA } \\
\text { and may help prevent } \\
\text { hypertension }\end{array}$ \\
\hline ALAjMI [49] & 2007 & $\begin{array}{l}10 \text { RCTs } \\
\text { (3 crossover } \\
\text { design, } \\
7 \text { parallel } \\
\text { design) }\end{array}$ & $\begin{array}{l}\text { Mean change } \\
\text { in systolic and } \\
\text { diastolic BP }\end{array}$ & $\begin{array}{l}\text { Systolic BP }-1.38 \\
(3.6--0.88) \mathrm{mmHg} \\
\text { Diastolic BP }-1.52 \\
(3.11--0.07) \mathrm{mmHg}\end{array}$ & $\begin{array}{l}\text { CPAP has very modest } \\
\text { effects on BP } \\
\text { Cannot exclude } \\
\text { possibility that certain } \\
\text { subgroups may have } \\
\text { more robust responses } \\
\text { including patients with } \\
\text { more severe OSA or } \\
\text { difficult-to-control } \\
\text { hypertension }\end{array}$ \\
\hline $\begin{array}{l}\text { HAENTJENS } \\
{[51]}\end{array}$ & 2007 & $\begin{array}{l}12 \text { RCTs } \\
\text { (6 crossover } \\
\text { design, } \\
6 \text { parallel } \\
\text { design) }\end{array}$ & $\begin{array}{l}\text { Change in } 24-\mathrm{h} \\
\text { ambulatory } \\
\text { MBP }\end{array}$ & $\begin{array}{l}\text { MBP }-1.69 \\
(-2.69--0.69) \mathrm{mmHg} \\
\text { MBP would decrease by } \\
1.39 \mathrm{mmHg} \text { for each } 1-\mathrm{h} \\
\text { increase in effective nightly } \\
\text { use of CPAP }\end{array}$ & $\begin{array}{l}\text { CPAP reduces } 24-h \\
\text { ambulatory MBP, with } \\
\text { greater treatment related } \\
\text { reductions in ambulatory } \\
\text { MBP among patients } \\
\text { with a more severe } \\
\text { degree of OSA and a } \\
\text { better effective nightly } \\
\text { use of the CPAP device }\end{array}$ \\
\hline
\end{tabular}

Data are presented as mean $(95 \% \mathrm{CI})$. RCT: randomised controlled trial; BP: blood pressure; MAP: mean arterial pressure; MBP: mean BP.

failed to find any improvement in glycaemic control or insulin resistance in 42 patients following CPAP therapy, while a more recent trial by LAM et al. [54] showed improvements in insulin sensitivity in moderately obese patients after 12 weeks of CPAP therapy. Again, interpretation of the available evidence is difficult given the limitations in the majority of these studies. These include limited sample size, exclusively male participants, lack of adequate control for confounding variables in nonrandomised trials and issues of CPAP compliance.

\section{Risk stratification of OSA patients}

Despite evidence that CPAP is a cost-effective therapy for the treatment of OSA, the inability to accurately identify patients who will benefit from treatment is problematic. The variable response to treatment may explain the heterogeneous results from CPAP trials to date. Although healthcare utilisation and cost have been shown to be a reliable measure of morbidity, the distribution of this measure is not normal among OSA patients [35, 55]. For this reason, the ability to identify patients with clinically relevant sequelae or increased health care utilisation would allow healthcare planners to more effectively target funding towards atrisk patients. Although OSA severity, based on standard $\mathrm{AHI}$ criteria, is often used to identify those at risk of increased morbidity, it appears that we cannot rely on a single measure to adequately identify high-risk groups. Recent publications suggest the presence of daytime sleepiness and oxygen desaturation profile may be two factors of particular importance.

\section{Excessive daytime sleepiness}

Hypersomnolence may identify specific subgroups at risk for poor health outcomes. The 
notion that OSA patients who are sleepy have a different risk profile than nonsleepy patients has been raised in the context of long-term cardiovascular disease, metabolic dysfunction and response to CPAP therapy. KAPUR et al. [56] showed that daytime sleepiness modified the association between OSA and hypertension among subjects in the Sleep Heart Heath Study. Specifically, the odds of hypertension were 2.83 among subjects with severe OSA $(A H I \geqslant 30$ events per $h$ ) who reported daytime sleepiness, compared with 1.22 for subjects with severe OSA who did not report daytime sleepiness [56]. Similarly, severe OSA has also been independently associated with diabetes mellitus exclusively in patients who report excessive sleepiness [24].

While a more recent study demonstrated a benefit from CPAP in nonsleepy patients [57], there were several design limitations, including retrospective analysis, post hoc selection and a lack of blinding. However, as mentioned previously, the preliminary results from the more rigorously designed MOSAIC trial show a lack of benefit from CPAP on cardiovascular end-points in minimally sleepy patients.

Our group has also shown that excessive daytime sleepiness is a risk factor for increased healthcare utilisation among patients referred for assessment of OSA. In a clinic-based cohort of 2,149 adults, excessive daytime sleepiness was associated with an increased rate of outpatient physician visits after adjustment for demographic variables, sleep medication use, comorbidity and OSA severity (rate ratio (RR) $1.09,95 \% \mathrm{Cl} 1.01-1.18$ ) compared with nonsleepy subjects [38]. Healthcare use was even higher among patients with severe OSA and sleepiness (RR 1.22, 95\% Cl 1.06-1.41). Similarly, the Sleep Heart Health Study found an $11 \%$ increase in healthcare use amongst sleepy subjects compared with those with no sleepiness, although this study used an indirect measure of healthcare use [37].

\section{Desaturation profile}

Measures of nocturnal hypoxaemia derived from polysomnography or ambulatory monitoring have been shown to be independent predictors of cardiovascular and metabolic outcomes in OSA patients $[38,58,59]$. PUNJABI et al. [59] demonstrated that adjustment of the diagnostic threshold based on oxygen saturation can have significant effects on previously accepted associations between OSA and cardiovascular disease. Hypopnoeas with desaturations of $<4 \%$ were not associated with cardiovascular disease, while those accompanied by $\geqslant 4 \%$ oxygen desaturation were independently associated with cardiovascular disease. Similarly, desaturation profile was identified as an independent predictor of increased healthcare use in a large clinic-based cohort. Spending $>12 \%$ of the total sleep time at an oxygen saturation of $<90 \%$ resulted in a $33 \%$ increase in the physician visits, irrespective of OSA severity [38].

While hypoxaemia and sleepiness appear to be associated with increased risk of comorbidity and healthcare use, it is important to recognise other contributory factors, such as age and socioeconomic status [55, 6o-62]. An ageing population continues to place a heavy burden on healthcare resources. In the setting of OSA, TARASIUK et al. [62] have shown that healthcare use and costs are greater in elderly populations compared with middle-aged populations, due to increased cardiovascular morbidity and need for prescription drugs. Similarly, socioeconomic status has been shown to be an independent risk factor for cardiovascular disease and adherence to CPAP among OSA populations [55, 61].

\section{Conclusion}

OSA is a common chronic condition and has major economic and health implications. Observational data show strong associations between OSA and comorbid conditions, including hypertension, coronary artery disease, stroke and diabetes, as well as increased healthcare resource utilisation. Whether OSA is an independent reversible risk factor for some of these conditions remains to be determined. Despite this evidence, the fact that OSA still remains underdiagnosed supports the need for additional education at the primary care level to increase the level of suspicion of OSA.

CPAP is the therapy of choice for OSA, and has consistently been shown to improve quality of life. However, it is important to recognise that, regardless of treatment effect, treatment adherence is necessary to improve health outcomes. No single factor has been consistently identified as predictive of CPAP acceptance and adherence. Understanding obstacles associated with a patient's decision to accept CPAP represents an area for future research. 
Moreover, not all patients benefit from treatment. Evidence to suggest that CPAP can reduce morbidity is variable, and little is known about the effect of CPAP on reducing healthcare use and associated costs at the population level. Factors that can be used $a$ priori to identify subgroups of OSA patients who will benefit from treatment have not been identified. Recent work suggests that the heterogeneity observed in clinical results may be driven by the inability to select at-risk groups. Further work in this area is required to establish a prediction tool to identify the patients with OSA who may benefit the most from treatment and target care to those at greatest risk.

\section{REFERENCES:}

1. Bixler EO, Vgontzas AN, Lin HM, et al. Prevalence of sleep-disordered breathing in women: effects of gender. Am J Respir Crit Care Med 2001; 163: 608-613.

2. Young T, Palta M, Dempsey J, et al. The occurrence of sleep-disordered breathing among middle-aged adults. N Engl J Med 1993; 328: 1230-1235.

3. Young T, Peppard PE, Gottlieb DJ. Epidemiology of obstructive sleep apnea: a population health perspective. Am J Respir Crit Care Med 2002; 165 : 1217-1239.

4. Reuveni H, Tarasiuk A, Wainstock T, et al. Awareness level of obstructive sleep apnea syndrome during routine unstructured interviews of a standardized patient by primary care physicians. Sleep 2004; 27: 1518-1525.

5. Kushida CA, Efron B, Guilleminault C. A predictive morphometric model for the obstructive sleep apnea syndrome. Ann Intern Med 1997; 127: $581-587$.

6. Young T, Peppard PE, Taheri S. Excess weight and sleep-disordered breathing. J Appl Physiol 2005; 99: 1592-1599.

7. Finkelstein EA, Trogdon JG, Cohen JW, et al. Annual medical spending attributable to obesity: payer-and service-specific estimates. Health Aff (Millwood) 2009; 28: 822-831.

8. Marin JM, Carrizo SJ, Vicente E, et al. Long-term cardiovascular outcomes in men with obstructive sleep apnoea-hypopnoea with or without treatment with continuous positive airway pressure: an observational study. Lancet 2005; 365: 1046-1053.

9. Nieto FJ, Young TB, Lind BK, et al. Association of sleep-disordered breathing, sleep apnea, and hypertension in a large community-based study. Sleep Heart Health Study. JAMA 2000; 283: 1829-1836.

10. Reichmuth KJ, Austin D, Skatrud JB, Young T. Association of sleep apnea and type II diabetes: a population-based study. Am J Respir Crit Care Med 2005; 172: 1590-1595.

11. Yaggi HK, Concato J, Kernan WN, et al. Obstructive sleep apnea as a risk factor for stroke and death. N Engl J Med 2005; 353: 2034-2041.

12. Peppard PE, Young T, Palta M, et al. Prospective study of the association between sleep-disordered breathing and hypertension. N Engl J Med 2000; 342: 1378-1384.

13. Arzt M, Young T, Finn L, et al. Association of sleepdisordered breathing and the occurrence of stroke. Am J Respir Crit Care Med 2005; 172: 1447-1451.

14. D'Alessandro R, Magelli C, Gamberini G, et al. Snoring every night as a risk factor for myocardial infarction: a case-control study. BMJ 1990; 300: 1557-1558.

15. Mooe T, Rabben T, Wiklund U, et al. Sleepdisordered breathing in men with coronary artery disease. Chest 1996; 109: 659-663.
16. Good DC, Henkle JQ, Gelber D, et al. Sleepdisordered breathing and poor functional outcome after stroke. Stroke 1996; 27: 252-259.

17. Johnson KG, Johnson DC. Frequency of sleep apnea in stroke and TIA patients: a meta-analysis. J Clin Sleep Med 2010; 6: 131-137.

18. Martinez-Garcia MA, Soler-Cataluna JJ, EjarqueMartinez L, et al. Continuous positive airway pressure treatment reduces mortality in patients with ischemic stroke and obstructive sleep apnea: a 5-year follow-up study. Am J Respir Crit Care Med 2009; 180: 36-41.

19. Sahlin C, Sandberg O, Gustafson Y, et al. Obstructive sleep apnea is a risk factor for death in patients with stroke: a 10-year follow-up. Arch Intern Med 2008; 168: 297-301.

20. Einhorn D, Stewart DA, Erman MK, et al. Prevalence of sleep apnea in a population of adults with type 2 diabetes mellitus. Endocr Pract 2007; 13: 355-362.

21. Ip MS, Lam B, Ng MM, et al. Obstructive sleep apnea is independently associated with insulin resistance. Am J Respir Crit Care Med 2002; 165: 670-676.

22. Punjabi NM, Sorkin JD, Katzel LI, et al. Sleepdisordered breathing and insulin resistance in middle-aged and overweight men. Am J Respir Crit Care Med 2002; 165: 677-682.

23. Marshall NS, Wong KK, Phillips CL, et al. Is sleep apnea an independent risk factor for prevalent and incident diabetes in the Busselton Health Study? J Clin Sleep Med 2009; 5: 15-20.

24. Ronksley PE, Hemmelgarn BR, Heitman SJ, et al. Obstructive sleep apnoea is associated with diabetes in sleepy subjects. Thorax 2009; 64: 834-839.

25. Ferrier K, Campbell A, Yee B, et al. Sleep-disordered breathing occurs frequently in stable outpatients with congestive heart failure. Chest 2005; 128: 2116-2122.

26. Wang $H$, Parker JD, Newton GE, et al. Influence of obstructive sleep apnea on mortality in patients with heart failure. J Am Coll Cardiol 2007; 49: 1625-1631.

27. Guilleminault C, Connolly SJ, Winkle RA. Cardiac arrhythmia and conduction disturbances during sleep in 400 patients with sleep apnea syndrome. Am J Cardiol 1983; 52: 490-494.

28. Mehra R, Benjamin EJ, Shahar E, et al. Association of nocturnal arrhythmias with sleep-disordered breathing: The Sleep Heart Health Study. Am J Respir Crit Care Med 2006; 173: 910-916.

29. Bahammam A, Delaive K, Ronald J, et al. Health care utilization in males with obstructive sleep apnea syndrome two years after diagnosis and treatment. Sleep 1999; 22: 740-747.

30. Banno K, Ramsey C, Walld R, et al. Expenditure on health care in obese women with and without sleep apnea. Sleep 2009; 32: 247-252.

31. Greenberg-Dotan S, Reuveni H, Simon-Tuval T, et al. Gender differences in morbidity and health care 
utilization among adult obstructive sleep apnea patients. Sleep 2007; 30: 1173-1180.

32. Kryger MH, Roos L, Delaive K, et al. Utilization of health care services in patients with severe obstructive sleep apnea. Sleep 1996; 19: S111-S116.

33. Reuveni H, Greenberg-Dotan S, Simon-Tuval T, et al. Elevated healthcare utilisation in young adult males with obstructive sleep apnoea. Eur Respir J 2008; 31: 273-279.

34. Ronald J, Delaive K, Roos L, et al. Health care utilization in the 10 years prior to diagnosis in obstructive sleep apnea syndrome patients. Sleep 1999; 22: 225-229.

35. Smith R, Ronald ), Delaive K, et al. What are obstructive sleep apnea patients being treated for prior to this diagnosis? Chest 2002; 121: 164-172.

36. Tarasiuk A, Greenberg-Dotan S, Brin YS, et al. Determinants affecting health-care utilization in obstructive sleep apnea syndrome patients. Chest 2005; 128: 1310-1314.

37. Kapur VK, Redline S, Nieto FJ, et al. The relationship between chronically disrupted sleep and healthcare use. Sleep 2002; 25: 289-296.

38. Ronksley PE, Hemmelgarn BR, Heitman SJ, et al. Excessive daytime sleepiness is associated with in creased health care utilization among patients referred for assessment of OSA. Sleep 2011; 34: 363-370.

39. Kapur V, Blough DK, Sandblom RE, et al. The medical cost of undiagnosed sleep apnea. Sleep 1999; 22: 749-755.

40. Sassani A, Findley LJ, Kryger M, et al. Reducing motor-vehicle collisions, costs, and fatalities by treating obstructive sleep apnea syndrome. Sleep 2004; 27: 453-458.

41. Kapur VK, Alfonso-Cristancho R. Just a good deal or truly a steal? Medical cost savings and the impact on the cost-effectiveness of treating sleep apnea. Sleep 2009; 32: 135-136.

42. Gay P, Weaver T, Loube D, et al. Evaluation of positive airway pressure treatment for sleep related breathing disorders in adults. Sleep 2006; 29: 381-401.

43. Peker Y, Hedner J, Johansson A, et al. Reduced hospitalization with cardiovascular and pulmonary disease in obstructive sleep apnea patients on nasal CPAP treatment. Sleep 1997; 20: 645-653.

44. Ayas NT, FitzGerald JM, Fleetham JA, et al. Costeffectiveness of continuous positive airway pressure therapy for moderate to severe obstructive sleep apnea/ hypopnea. Arch Intern Med 2006; 166: 977-984. effectiveness of nCPAP treatment in patients with moderate-to-severe obstructive sleep apnoea. Eur Respir J 2003; 21: 515-522.

46. Kapur VK. Obstructive sleep apnea: diagnosis, epidemiology, and economics. Respir Care 2010; 55: 1155-1167.

47. Whitelaw WA, Brant RF, Flemons WW. Clinical usefulness of home oximetry compared with polysomnography for assessment of sleep apnea. Am J Respir Crit Care Med 2005; 17: 188-193.

48. Flemons WW, Douglas NJ, Kuna ST, et al. Access to diagnosis and treatment of patients with suspected

sleep apnea. Am J Respir Crit Care Med 2004; 169: 668-672.

49. Alajmi M, Mulgrew AT, Fox J, et al. Impact of continuous positive airway pressure therapy on blood pressure in patients with obstructive sleep apnea hypopnea: a meta-analysis of randomized controlled trials. Lung 2007; 185: 67-72.

50. Bazzano LA, Khan Z, Reynolds K, et al. Effect of nocturnal nasal continuous positive airway pressure on blood pressure in obstructive sleep apnea. Hypertension 2007; 50: 417-423.

51. Haentjens P, Van Meerhaeghe A, Moscariello A, et al. The impact of continuous positive airway pressure on blood pressure in patients with obstructive sleep apnea syndrome: evidence from a meta-analysis of placebo-controlled randomized trials. Arch Intern Med 2007; 167: 757-764.

52. Craig SE, Kohler M, Nicoll D, et al. Does continuous positive airway pressure (CPAP) for minimally symptomatic obstructive sleep apnoea (OSA) reduce calculated cardiovascular risk? Primary results from MOSAIC, a randomized controlled trial. Am J Respir Crit Care Med 2011; 183: A2201.

53. West SD, Nicoll DJ, Wallace TM, et al. Effect of CPAP on insulin resistance and $\mathrm{HbAlc}_{\mathrm{C}}$ in men with obstructive sleep apnoea and type 2 diabetes. Thorax 2007; 62: 969-974.

54. Lam JC, Lam B, Yao TJ, et al. A randomised controlled trial of nasal continuous positive airway pressure on insulin sensitivity in obstructive sleep apnoea. Eur Respir J 2010; 35: 138-145.

55. Tarasiuk A, Greenberg-Dotan S, Simon T, et al. Low socioeconomic status is a risk factor for cardiovascular disease among adult obstructive sleep apnea syndrome patients requiring treatment. Chest 2006; 130: 766-773.

56. Kapur VK, Resnick HE, Gottlieb DJ. Sleep disordered breathing and hypertension: does self-reported sleepiness modify the association? Sleep 2008; 31: 1127-1132.

57. Barbe F, Duran-Cantolla J, Capote F, et al. Long-term effect of continuous positive airway pressure in hypertensive patients with sleep apnea. Am J Respir Crit Care Med 2010; 181: 718-726.

58. Ahmed SB, Ronksley PE, Hemmelgarn BR, et al. Nocturnal hypoxia and loss of kidney function. PLoS One 2011; 6: e19029.

59. Punjabi NM, Newman AB, Young TB, et al. Sleepdisordered breathing and cardiovascular disease: an outcome-based definition of hypopneas. Am J Respir Crit Care Med 2008; 177: 1150-1155.

6o. Launois SH, Pepin JL, Levy P. Sleep apnea in the elderly: a specific entity? Sleep Med Rev 2007; 11: 87-97.

61. Simon-Tuval T, Reuveni H, Greenberg-Dotan S, et al. Low socioeconomic status is a risk factor for CPAP acceptance among adult OSAS patients requiring treatment. Sleep 2009; 32: 545-552.

62. Tarasiuk A, Greenberg-Dotan S, Simon-Tuval T, et al. The effect of obstructive sleep apnea on morbidity and health care utilization of middle-aged and older adults. J Am Geriatr Soc 2008; 56: 247-254. 